\title{
Acetylation may strengthen the antitumor activity of low molecular heparin
}

\author{
Ying Liang ${ }^{1,2 \#}$, Yuanyuan Wang ${ }^{3}$, Guowen Wang ${ }^{4}$, Ansheng Wang ${ }^{4}$, Kangwu Wang $^{4}$, Guixin Duan ${ }^{4 \#}$ \\ ${ }^{1}$ Anhui Engineering Technology Research Center of Biochemical Pharmaceuticals, Bengbu, China; ${ }^{2}$ School of Pharmacy, Bengbu Medical College, \\ Bengbu Anhui, China; ${ }^{3}$ School of Basic Medical, Bengbu Medical College, Bengbu, China; ${ }^{4}$ Department of Thoracic Surgery, the First Affiliated \\ Hospital of Bengbu Medical College, Bengbu, China \\ Contributions: (I) Conception and design: Y Liang, Y Wang; (II) Administrative support: G Wang, G Duan; (III) Provision of study materials or \\ patients: A Wang, K Wang; (IV) Collection and assembly of data: Y Liang; (V) Data analysis and interpretation: Y Liang; (VI) Manuscript writing: \\ All authors; (VII) Final approval of manuscript: All authors. \\ \#These authors contributed equally to this work. \\ Correspondence to: Guowen Wang. Department of Thoracic Surgery, the First Affiliated Hospital of Bengbu Medical College, 287 Changhuai Road, \\ Bengbu 233010, China. Email: wgwzj@163.com; Guixin Duan. Department of Cardiothoracic Surgery, the First Affiliated Hospital of Bengbu \\ Medical College, 287 Changhuai Road, Bengbu 233010, China. Email: guixinduan@aliyun.com; guixinduan@yeah.net.
}

Background: To synthesize acetylated low anticoagulant low molecular weight heparin (ALMWH) and to detect its antineoplastic activity.

Methods: We obtained Low anticoagulant low molecular weight heparin (LMWH) by splitting unfractionated heparin (UFH) with sodium periodate oxidation and sodium borohydride reduction, then the LMWH was subjected to acetylate catalyzed by dicyclohexylcarbodiimide and dimethylaminopyridine to produce ALMWH. The anti-proliferative activities were determined on MDA-MB-231 human breast cancer cells in vitro.

Results: ALMWH exhibited stranger anti-proliferative activity Compared with LMWH, In the MDAMB-231 cell line, the growth of MDA-MB-231 cells with IC50 of $22.16 \mu M$ at $48 \mathrm{~h}$ in a concentrationdependent and time-dependent manner, ALMWH produced stronger inhibitory effects especially when it was used in low concentrations. By the use of bulky catalysts, the acetylation site in the molecular chain of low molecular weight heparin with a high selectivity, the synthesis process of Low anticoagulant low molecular weight heparin can be easily controlled. Therefore, large scale industrial production can be carried out.

Conclusions: The synthesized ALMWH possesses a high anti-proliferative activity, Chemical modification of structure can endow LMWH with a high antiproliferative activities. ALMWH is expected to enter clinical trials due to its high druggability. Simultaneously, this study provides a basic method for screening of antineoplastic drug with low toxicity.

Keywords: Acetylated low molecular weight heparin (ALMWH); MDA-MB-231 cells; antitumor; drug; heparan sulfate

Submitted Apr 26, 2020. Accepted for publication Jan 02, 2021.

doi: $10.21037 /$ tcr-20-2195

View this article at: http://dx.doi.org/10.21037/tcr-20-2195

\section{Introduction}

Low molecular weight heparin (LMWH) has undergone sixty years of history since 1933. It has been used as an anticoagulant. Much research has shown that LWMH possesses antitumor activity except its anticoagulation and antithrombosis. The antitumor mechanisms may involve a double mechanism of the anticoagulation and non-anticoagulation. LMWH (1-7) promotes vascular 
endothelium release tissue factor pathway inhibitor (TFPI), inhibits the highly expressed of tissue factor (TF) on tumor cells, suppresses local thrombin production on tumor and blocks the generation of local coagulation, reduces the formation of fibrin-platelet-tumor clot, and creates convenient conditions for the defense system to fight tumor cells. LWMH inhibits the activation of platelet, reduces the release of selectin, suppresses tumor cell adhere to the endothelial cell to limit adherence, invasion, and metastasis of tumor cell. The inhibition of LMWH on heparanase reduces the degradation of the enzyme on heparin sulfate (HS) and reduce the release of a growth factor such as basic fibroblast growth factor (bFGF) and Vascular endothelial growth factor (VEGF) (8-11), consequently suppresses the proliferation and blood vessel vascular formation of a tumor, and strengthen the barrier such as basement membrane and extracellular matrix blocking invasion and metastasis of tumor cells. However, like heparin, LMWH is limited in the antineoplastic application because of its low antitumor activity and insurmountable adverse reaction such as bleeding and thrombocytopenia. How to elevate LMWH's antitumor activity and lower its adverse reaction? A current research focus is forming.

In 2002, our group confirmed that heparan sulfate (HS) synthesized by normal human breast epithelial cells has a significant inhibitory effect on the proliferation of MDAMB-231 and MCF-7 cells $(12,13)$.

In 2008, Our group found that HS extracted from human breast cancer MCF-7 cells also has a significant inhibitory effect on breast cancer xenograft $\mathrm{C} 3 \mathrm{H}$ mouse model (14), suggested that HS is an endogenous substance synthesized and secreted by cells and used to regulate their own proliferation activities probably. The low molecular weight heparin a glycosaminoglycan, is similar to heparan sulfate in structure and has anti-tumor cell invasion and metastasis activity (7). In 2015, it was found that acetylated Low anticoagulant low molecular heparin (ALMWH) was increased in alkalinity due to cationization, which changed from acidic oligosaccharides to amphoteric oligosaccharides. The affinity to the organism was enhanced and acetylation modification made this amphoteric oligosaccharide molecule. The chains are linear in aqueous solution and have a tendency to self-assemble into linear aggregates, which are easy to enter cells and enhance their anti-breast cancer cell proliferation activity (15).

Therefore, our group continues to research the antiproliferation effect and the mechanism on human breast cancer MDA-MB-231 cell.

\section{Methods}

We obtained LMWH and Unfractionated heparin (Jiangsu Wan Bang Company Limited, $M W<8,000$ Da), human breast cancer cell line (American Type Culture Collection), tributyl ammonium salt, acetic acid and acetic anhydride, DCC, DMAP (Sinopharm Chemical reagent Co, Lid), diethyl ether (The Wuxi City Chemical Co, Lth), $\mathrm{CO}_{2}$ incubator (THERMO Forma), DMEM (Gibco), SCM (Hangzhou Four Seasons), and automatic cell counter (Shanghai RUIYU Biological Technology Co, LTD) for use in this study.

\section{Preparation and characterization of the low anticoagulant acetylated low-molecular-weight beparin (ALMWH)}

Low anticoagulant low molecular-weight heparin (LMWH) was prepared by the oxidation-reduction method. Briefly, heparin $(1 \mathrm{~g})$ was dissolved in water $(10 \mathrm{~mL})$, oxidized using sodium periodate $(200 \mathrm{mg})$, and reduced using sodium borohydride $(100 \mathrm{mg})$ to obtain LMWH $(500 \mathrm{mg})$. LMWH $(500 \mathrm{mg})$ was re-dissolved in water $(10 \mathrm{~mL})$. Thereafter, dimethyl sulfoxide (DMSO: $190 \mathrm{~mL}$ ) was added to achieve a volume ratio of 5:95 for water to DMSO. The reaction was carried out at $50{ }^{\circ} \mathrm{C}$ for $2 \mathrm{~h}$. The desulphated LMWH (300 mg) was obtained.

The desulphated LMWH (300 mg) was dissolved in distilled water $(10 \mathrm{~mL})$. Thereafter, Tri-n-ethylammonium $(1 \mathrm{~mL})$ was added to the eluent, lyophilized, and redissolved in dichloromethane. DCC $(30 \mathrm{mg})$ and acetic anhydride $(1 \mathrm{~mL})$ were added to the solution with stirring for $4 \mathrm{~h}$ at $20^{\circ} \mathrm{C}$. Subsequently, $\mathrm{NaOH}$ solution $(5 \%, 5 \mathrm{~mL})$ was added dropwise to the reaction solution. After stirring for $7 \mathrm{~h}$, the solution was filtered. The filtrate was adjusted to $\mathrm{pH}$ 7.0, decontaminated with diethyl ether, concentrated via decompression, and passed through the column. The desired fraction was collected and concentrated via decompression. The off-white powder of acetylated LMWH was obtained (ALMWH: $150 \mathrm{mg}$ ). The structures of LMWH and ALMWH were confirmed by ${ }^{1} \mathrm{HNMR}$ at $30{ }^{\circ} \mathrm{C}$. The degree of acetylation was calculated according to the following formula:

Degree of acetylation $(\%)=$
$\left[\frac{\text { acetyl intensities (ALMWH) - acetyl intensities (LMWH) }}{\text { acetyl intensities (LMWH) }}\right] \times 100 \%$

\section{Concentration of ALMWH and LMWH}

The concentration of ALMWH and LMWH is prepared 
according to the Weight concentration. The ALMWH and LMWH was dissolved in phosphate-buffered saline to prepare Different concentrations of ALMWH for use.

\section{Effects of ALMWH on the growth of MDA-MB-231 cells}

MDA-MB-231 cells were seeded at $2.5 \times 10^{4}$ cells/well into a 6-well tissue culture plate filled with $0.5 \mathrm{~mL}$ of DMEM (containing $7 \% \mathrm{FBS}$ ) at $37{ }^{\circ} \mathrm{C}, 95 \%$ air, $5 \% \mathrm{CO}_{2}$, and damp-warm condition. Cells were allowed to grow for $48 \mathrm{~h}$. Thereafter, the medium was changed to DMEM containing a low concentration of FBS $(0.5 \%)$ and culture was continued for an additional 24, 48 and $72 \mathrm{~h}$. After treatment with different concentrations of ALMWH, Free cells were released with trypsin, the cells were collected and the cell numbers were counted respectively, tumor growth curve was drawn and IC 50 value of tumor cells at were measured. The percent cell viability was calculated using the following formula:

Cell Viability $(\%)=$

$\left[\frac{\text { the cell number of intervening group }}{\text { the cell number of control group }}\right] \times 100 \%$

\section{Statistical analysis}

Statistical data are expressed as $\bar{x} \pm \mathrm{s}$. Dunnett- $t$ test was performed using SPSS 13.0 statistical software. Data are expressed as mean with $95 \%$ confidence intervals.

\section{Results}

Preparation of the low anticoagulant acetylated lowmolecular-weight beparin (ALMWH)

Using the redox method we have been successful degrade heparin into low anticoagulant low molecular weight heparin (LMWH), using bluk catalysts dicyclohexylcarbodiimide (DCC) and dimethylaminopyridine (DMAP), the The hydroxyl group of LMWH sugar chain was selectively acetylated, and the acetylated low anticoagulant low molecular weight heparin (ALMWH) was obtained. The acetylation rate of ALMWH was $12.0 \%$, and the acetylation rate of low anticoagulation low molecular weight heparin (LMWH) was $3.32 \%$ by the analysis of proton nuclear magnetic of polysaccharide at $2 \mathrm{ppm}$.
ALMWH inbibits MDA-MB-231 cells growth in a dosedependent manner

ALMWH significantly inhibits MDA-MB-231 cell growth (Table 1 and Figure 1). The inhibition tended to be enhanced with the increase of drug doses (Figure 2), and the antiproliferation of ALMWH on MDA-MB-231 cells is distinctly more significant than LMWH when the dose of ALMWH is equivalent to LMWH's dose.

\section{ALMWH inbibits MDA-MB-231 cells growth in a time- dependent manner}

The counting results of the MDA-MB-231 cells after treatments of the different drugs, different doses of ALMWH, and different treatment times are shown in Table 1 and Figure 3. The antiproliferative effects on MDAMB-231 cells shows time-dependent when the dose of the given ALMWH is larger than $0.5 \mathrm{mg} / \mathrm{mL}$. ALMWH's antiproliferation on MDA-MB-231 cells is beyond ALMWH, while the given dose of ALMWH is equal to LMWH $(1.5 \mathrm{mg} / \mathrm{mL})$. The growth inhibition of ALMWH treatment for $72 \mathrm{~h}$ on MDA-MB-231 cells is superior to the given dose of paclitaxel.

\section{Cell viability study}

ALMWH displayed dose-dependent cytotoxicity in the concentration range of $0.05-1.5 \mathrm{mg} / \mathrm{mL}$. The IC50 of ALMWH in $48 \mathrm{~h}$ on breast cancer MDA-MB-231 cells is $22.16 \mu \mathrm{M}$.

\section{Discussion}

HS is synthesized and secreted by many cells; it is an endogenous antiproliferative molecule and exerts multifunction such as regulating cell adherence, proliferation, vascular generation, and tumor metastasis (16). Much research has proven that normal cell synthesized HS may inhibit the proliferation of tumor cells, suppress tumor vasculogenesis, and prevent tumor cell adherence, invasion as well as metastasis $(14,17-21)$. The antiproliferative activity of HS exists in highly sulfated domains, which are enriched in hexuronate 2 -sulfate residues and have a minimum length of 4-5 disaccharide units (22). The anticancer mechanism may involve inhibition of heparanase 


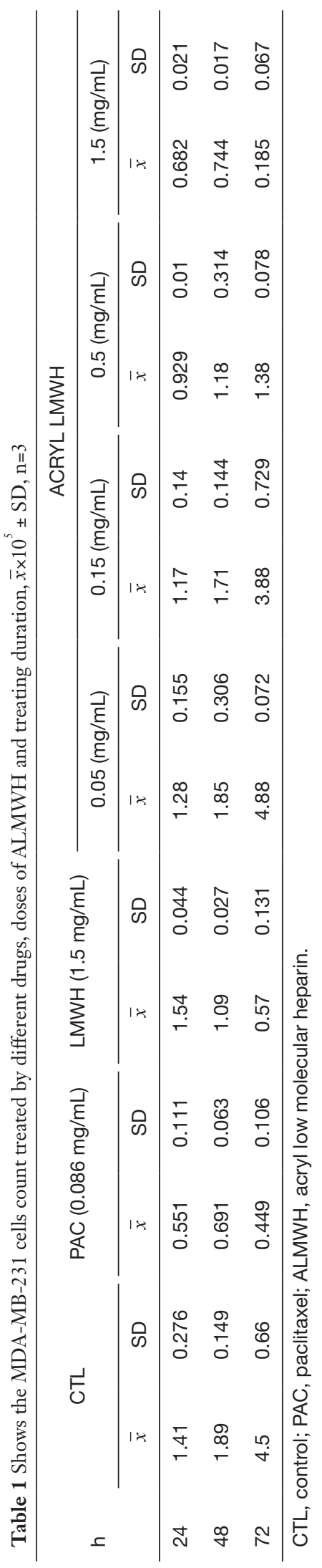

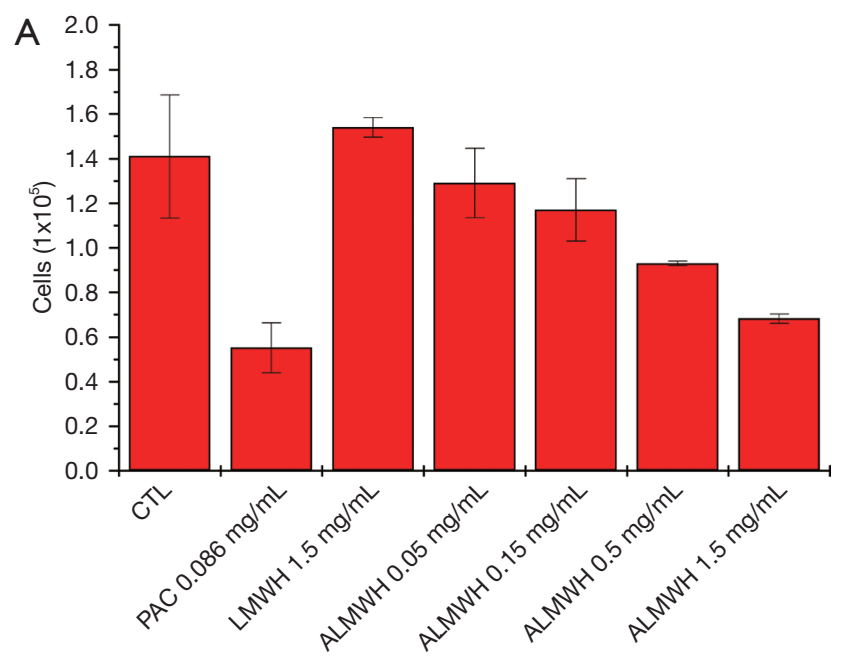
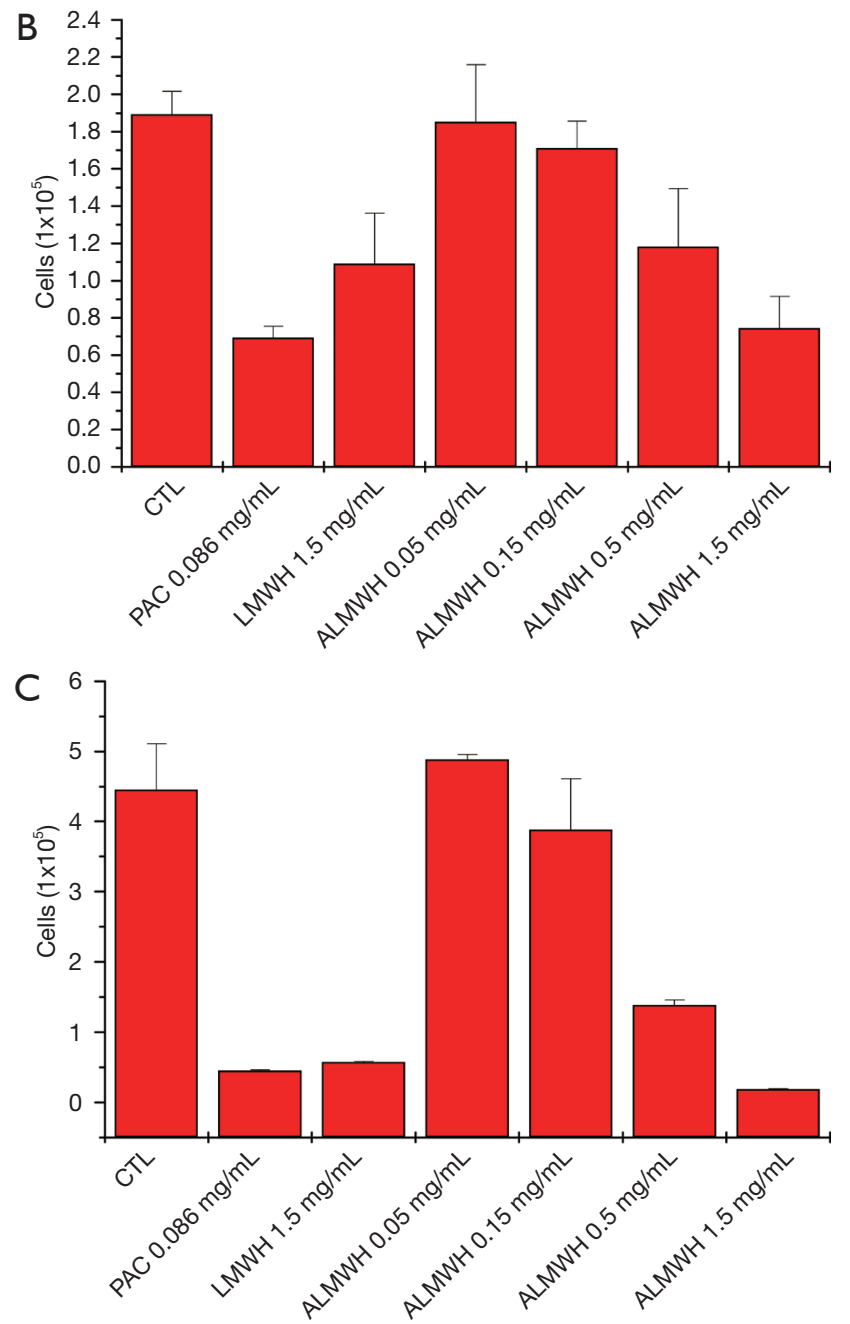

Figure 1 Inhibition of ALMWH on MDA-MB-231 proliferation. $(\mathrm{A}, \mathrm{B}, \mathrm{C})$ represent 24,48 , and $72 \mathrm{~h}$ of treating duration, respectively. CTL, control; PAC, paclitaxel; LMWH, low molecular heparin; ALMWH, acryl LMWH. 


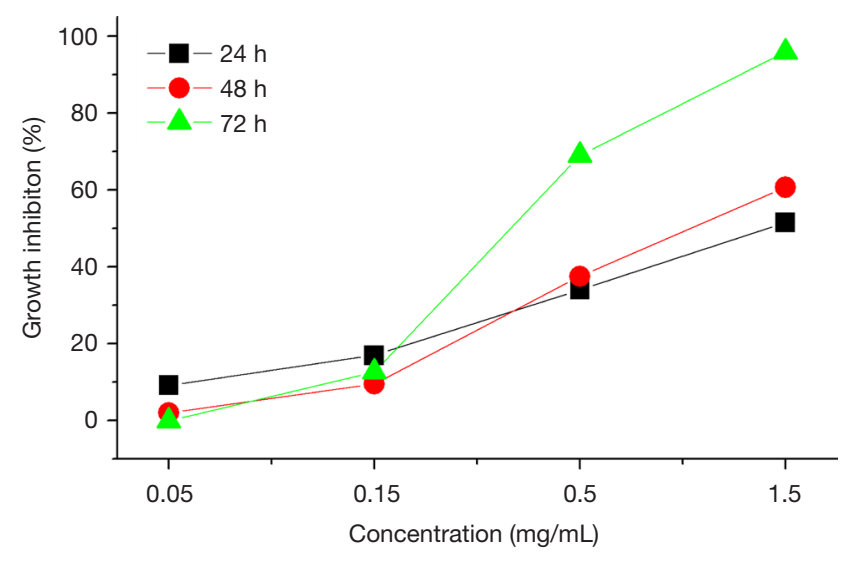

Figure 2 The antiproliferative effects of ALMWH on the MDAMB-231 cells. ALMWH, acryl low molecular heparin.

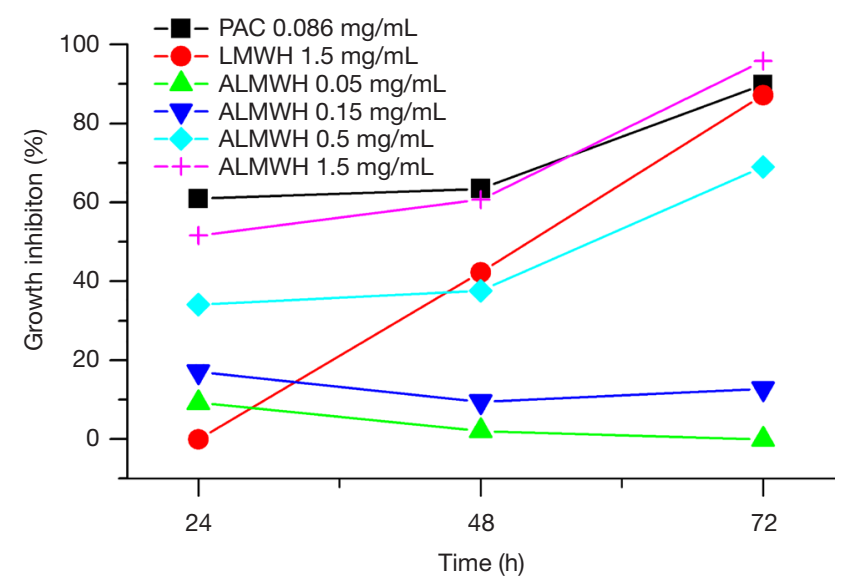

Figure 3 Antiproliferative effects of different durations of drug treatment on MDA-MB-231 cells. CTL, control; PAC, paclitaxel; LMWH, low molecular heparin; ALMWH, acryl LMWH.

and on the expression of VEGF as well as induction of apoptosis. Thus, HS may be an excellent therapeutic candidate for cancer therapy. Unfortunately, the complexity of extraction and purification and low-yield rate for HS makes an outstanding contribution to limit its clinical application.

Like HS, HP is composed of the same repeating disaccharide subunits; however, its primary structure differs significantly from that of heparin. The disaccharide subunits are present in diferent proportions, with the GlcA/ IdoA and GlcNAc/GlcNS ratios lower and the $\mathrm{SO}_{4}$ content higher. The GlcNS to GlcNAc ratio is 1:1 in HS vs. >4:1 in heparin (23).
Heparin commonly used in the clinic is called unfractionated heparin (UFH). It is challenging to apply $\mathrm{UFH}$ to antineoplastic therapy though it can improve cancer patients' survival time (24-27), inhibit tumor growth and metastasis (27-34) because of its weak antitumor activity and more significant anticoagulant activity. LMWHs are the enzymatic or chemical degradation, and the mean molecular weight is about $5 \mathrm{kD}$. The majority of LMWH chains are too short of forming LMWHAT-IIa triple complex. Thus, LMWH has little anti-IIa activity compared to UFH (35). LMWH presents essential advantages compared to UFH: enhanced bioavailability after subcutaneous administration, prolonged half-life, and more interesting pharmacokinetic properties, reduced thrombocytopenia, and a more predictable dose-response (36-38). However, bleeding and thrombocytopenia adverse reactions still limit the larger dose and longterm use of LMWHs (39). Chain flexibility, the degree of sulfation (charge density), and the proper distribution of $\mathrm{N}$-sulfate and $\mathrm{N}$-acetyl groups (charge distribution) along the LMWH molecule provide convenience for chemical modification. Garg et al. found that O-sulfonation fully did not enhance the growth inhibition properties of UFH (40). Meanwhile, both $\mathrm{N}$-sulfo and $\mathrm{N}$-acetyl are essential for the growth inhibition properties (41), and the loss of 6-O-sulfo groups in GlcN residues decreases growth inhibition properties of UFH (42). Furthermore, the 2-O-sulfo group of L-iduronic acid residues in UFH are significantly crucial for its growth inhibition properties (43), and hexanoylation at 3-O-position increased the growth inhibition properties of UFH (44). Gohda et al. (45) found that the alkylated HP, after treatment with an oxidizing agent reduces the growth rate of SMCs by an increase in the alkyl group chain length. Earlier, Bârzu et al. (46) and Irimura et al. (47) also reported that growth inhibition properties of SMCs by O-acylated HP derivatives changed with the change in several carbon atoms present in their acyl chain. Other include $\mathrm{N}$-acetylation, N-desulfation, O-desulfation, and carboxylreduction, and so on $(48,49)$, chemical modification elevates the antitumor activity and reduce the anticoagulant activity as well as an adverse reaction of LMWH (50). We gained ALMWH through selective O-acetylation of LMWH, which shows excellent antineoplastic activity. The antineoplastic activity is stronger than the isodose LMWH, the growth inhibition of MDA-MB-231 treated for $72 \mathrm{~h}$ is slight the that of paclitaxel given dose. The result suggests that the O-acetylation of LMWH can elevate the antineoplastic activity of $\mathrm{LMWH}$. 


\section{Conclusions}

We designed and constructed an acetylated low anticoagulant low molecular heparin (ALMWH) with High biocompatibility and lower side effects. This system showed Enhanced antitumor effect to MDA-MB-231 cells in vitro and has potential benefit in cancer therapy.

\section{Acknowledgments}

Funding: Anhui School Science Research Project in Anhui Province (No. KJ2012A202, No. KJ2013b140 and No. KJ2018A0987).

\section{Footnote}

Data Sharing Statement: Available at http://dx.doi. org/10.21037/tcr-20-2195

Conflicts of Interest: All authors have completed the ICMJE uniform disclosure form (available at http://dx.doi. org/10.21037/tcr-20-2195). The authors have no conflicts of interest to declare.

Ethical Statement: The authors are accountable for all aspects of the work in ensuring that questions related to the accuracy or integrity of any part of the work are appropriately investigated and resolved.

Open Access Statement: This is an Open Access article distributed in accordance with the Creative Commons Attribution-NonCommercial-NoDerivs 4.0 International License (CC BY-NC-ND 4.0), which permits the noncommercial replication and distribution of the article with the strict proviso that no changes or edits are made and the original work is properly cited (including links to both the formal publication through the relevant DOI and the license). See: https://creativecommons.org/licenses/by-nc-nd/4.0/.

\section{References}

1. Amirkhosravi A, Mousa SA, Amaya M, et al. Antimetastatic effect of tinzaparin, a low-molecular-weight heparin. J Thromb Haemost 2003;1:1972-6.

2. Bobek V, Kovarik J. Antitumor and antimetastatic effect of warfarin and heparins. Biomed Pharmacother 2004;58:213-9.

3. Gasowska K, Naumnik B, Klejna K, et al. The influence of unfractionated and low-molecular weight heparins on the properties of human umbilical vein endothelial cells (HUVEC). Folia Histochem Cytobiol 2009;47:17-23.

4. Kuczka K, Baum K, Picard-Willems B, et al. Long term administration of LMWH- pharmacodynamic parameters under therapeutic or prophylactic regimen of enoxaparin or tinzaparin in neurological rehabilitation patients. Thromb Res 2009;124:625-30.

5. Mousa SA, Petersen LJ. Anti-cancer properties of lowmolecular-weight heparin: Preclinical evidence. Thromb Haemost 2009;102:258-67.

6. Vignoli A, Marchetti M, Balducci D, et al. Differential effect of the low-molecular-weight heparin, dalteparin, and unfractionated heparin on microvascular endothelial cell hemostatic properties. Haematologica 2006;91:207-14.

7. Niers TM, Klerk CP, DiNisio M, et al. Mechanisms of heparin induced anti-cancer activity in experimental cancer models. Crit Rev Oncol Hematol 2007;61:195-207.

8. Bitan M, Polliack A, Zecchina G, et al. Heparanase expression in human leukemias is restricted to acute myeloid leukemias. Exp Hematol 2002;30:34-41.

9. Elkin M, Ilan N, Ishai-Michaeli R, et al. Heparanase as mediator of angiogenesis: mode of action. FASEB J 2001;15:1661-3.

10. Vlodavsky I, Friedmann Y. Molecular properties and involvement of heparanase in cancer metastasis and angiogenesis. J Clin Invest 2001;108:341-7.

11. Kato M, Wang H, Kainulainen V, et al. Physiological degradation converts the soluble syndecan-1 ectodomain from an inhibitor to a potent activator of FGF-2. Nat Med 1998;4:691-7.

12. Jiang $Z$, Le Bourhis $X$, Hondermarck H, et al. Progressing growth of tumor Cell and synthesis of Bip/GRP78. Chinese Pharmacological Bulletin 2002;18:79-83.

13. Fadnes B, Rekdal Ø, Uhlin-Hansen L. The anticancer activity of lytic peptides is inhibited by heparan sulfate on the surface of the tumor cells. BMC Cancer 2009;9:183-96.

14. Liu H, Jiang Z, Tong X. Inhibitory effects of heparan sulfate proteoglycan on transplanted breast cancer in $\mathrm{C} 3 \mathrm{H}$ mice. Chinese Pharmacological Bulletin 2008;24:744-8.

15. Liang Y. PH-sensitive drug-loaded particle as well as preparation method and application there of china invention patent. ZL20151088743 5.7.2015.12.01. Available online: http://pss-system.cnipa.gov.cn/ sipopublicsearch/patentsearch/showViewListjumpToView.shtml

16. Islam T, Butler M, Sikkander SA, et al. Further evidence 
that periodate cleavage of heparin occurs primarily through the antithrombin binding site. Carbohydr Res 2002;337:2239-43.

17. Fritze LM, Reilly CF, Rosenberg RD. Antiproliferative heparan sulfate species produced by postconfluent smooth muscle cells. J Cell Biol 1985;100:1041-9.

18. Fedarko NS, Ishihara M, Conrad HE. Control of cell division in hepatoma cells by exogenous heparan sulfate proteoglycans. J Cell Physiol 1989;139:287-94.

19. Wang X, Liu H, Shi P, et al. Effects of heparan sulfate on Caspase-3 activity and expressions of Caspase-3, bc1-2 in mice breast tumor cells. The Journal of Practical Medicine 2008;24:2205-7.

20. Tong X, Dong S, Liu H, et al. Inhibition and induction of apoptosis in breast cancer cells by Heparan sulfate proteoglycan. The Journal of Practical Medicine 2008;24:3816-9.

21. Gong P, Liu H, Liu H, et al. Effects of heparin sufate on MDA-MB-231 cells' endoplasmic reticulum stress, heparanase expression and apoptosis. The Journal of Practical Medicine 2010;26:1707-10.

22. Schmit A, Yoshida K, Buddecke E. The antiproliferative activity of arterial heparin sulfate resides in domanis enriched 2-O-sulfated Uronic Acid Resides. J Boil Chem 1992;267:19242-7.

23. Rabenstein DL. Heparin and heparan sulfate: structure and function. Nat Prod Rep 2002;19:312-31.

24. Lazo-Langner A, Goss GD, Spaans JN, et al. The effect of low-molecular-weight heparin on cancer survival. A systematic review and meta-analysis of randomized trials. J Thromb Haemost 2007;5:729-37.

25. Sasisekharan R, Shriver Z, Venkataraman G, et al. Roles of heparan-sulphate glycosaminoglycans in cancer. Nat Rev Cancer 2002;2:521-8.

26. Klerk CP, Smorenburg SM, Otten HM, et al. The effect of low molecular weight heparin on survival in patients with advanced malignancy. J Clin Oncol 2005;23:2130-5.

27. Engelberg H. Actions of heparin that may affect the malignant process. Cancer 1999;85:257-72.

28. Niers TM, Klerk CP, DiNisio M, et al. Mechanisms of heparin induced anti-cancer activity in experimental cancer models. Crit Rev Oncol Hematol 2007;61:195-207.

29. Gao Y, Wei M, Zheng S, et al. Chemically modified heparin inhibits the in vitro adhesion of nonsmall cell lung cancer cells to P-selectin. J Cancer Res Clin Oncol 2006;132:257-64.

30. Hasan J, Shnyder SD, Clamp AR, et al. Heparin octasaccharides inhibit angiogenesis in vivo. Clin Cancer
Res 2005;11:8172-9.

31. Karti SS, Ovali E, Ozgur O, et al. Induction of apoptosis and inhibition of growth of human hepatoma HepG2 cells by heparin. Hepatogastroenterology 2003;50:1864-6.

32. Pross M, Lippert H, Misselwitz F, et al. Low-molecularweight heparin (reviparin) diminishes tumor cell adhesion and invasion in vitro, and decreases intraperitoneal growth of colonadeno-carcinoma cells in rats after laparoscopy. Thromb Res 2003;110:215-20.

33. Amirkhosravi A, Mousa SA, Amaya M, et al. Antimetastatic effect of tinzaparin, a low-molecular-weight heparin. J Thromb Haemost 2003;1:1972-6.

34. Mason HR, Nowak RA, Morton CC, et al. Heparin inhibits the motility and proliferation of human myometrial and leiomyoma smooth muscle cells. Am J Pathol 2003;162:1895-904.

35. Boneu B, Caranobe C, Cadroy Y, et al. Pharmacokinetic studies of standard unfractionated heparin, and low molecular weight heparins in the rabbit. Semin Thromb Hemost 1988;14:18-27.

36. Liang Y, Jiang Z, Liu H, et al. Polysaccharide acylate and preparation method thereof china invention patent. ZL201210574597.1. 2012.12.26. Available online: http:// pss-system.cnipa.gov.cn/sipopublicsearch/patentsearch/ showViewList-jumpToView.shtml

37. Khorana AA, Sahni A, Altland OD, et al. Heparin Inhibition of Endothelial Cell Proliferation and Organization Is Dependent on Molecular Weight. Arterioscler Thromb Vasc Biol 2003;23:2110-5.

38. Lee DY, Kim SK, Kim YS, et al. Suppression of angiogenesis and tumor growth by orally active deoxycholic acid-heparin conjugate. J Control Release 2007;118:310-7.

39. Hoppensteadt D, Walenga JM, Fareed J, et al. Heparin, Low-molecular-weight heparins and heparin pentasaccharide basic and clinical differentiation. Hematol Oncol Clin North Am 2003;17:313-41.

40. Garg HG, Yu L, Hales CA, et al. Effect of fully sulfated glycosaminoglycans on pulmonary artery smooth muscle cell proliferation. Arch Biochem Biophys 1999;371:228-33.

41. Longas MO, Garg HG, Trinkle-Pereira JM, et al. Heparin antiproliferative activity on bovine pulmonary artery smooth muscle cells requires both $\mathrm{N}$-acetylation and N-sulfonation. Carbohydr Res 2003;338:251-6.

42. Garg HG, Yu L, Hales CA, et al. Sulfation patterns in heparin and heparan sulfate: effects on the proliferation of bovine pulmonary artery smooth muscle cells. Biochim Biophys Acta 2003;1639:225-31. 
43. Garg HG, Mrabat H, Yu L, et al. Significance of the 2-O-sulfo group of L-iduronic acid residues in heparin on the growth inhibition of bovine pulmonary artery smooth muscle cells. Carbohydr Res 2008;343:2406-10.

44. Garg HG, Hales CA, Yu L, et al. Increase in the growth inhibition of bovine pulmonary artery smooth muscle cells by an O-hexanoyl low-molecular-weight heparin derivative. Carbohydr Res 2006;341:2607-12.

45. Gohda M, Magoshi T, Kato S, et al. Terminally alkylated heparin. 2.Potent antiproliferative agent for vascular smooth muscle cells. Biomacromolecules 2001;2:1178-83.

46. Bârzu T, Desmoulière A, Herbert JM, et al. O-acylated heparin derivatives with low anticoagulant activity decrease proliferation and increase alpha-smooth muscle actin expression in cultured arterial smooth muscle cells. Eur J Pharmacol 1992;219:225-33.

Cite this article as: Liang Y, Wang Y, Wang G, Wang A, Wang K, Duan G. Acetylation may strengthen the antitumor activity of low molecular heparin. Transl Cancer Res 2021;10(1):461468. doi: 10.21037/tcr-20-2195
47. Irimura T, Nakajima M, Nicolson GL. Chemically modiied heparins as inhibitors of heparan sulfate speciic endo-beta-glucuronidase (heparanase) of metastatic melanoma cells. Biochemistry 1986;25:5322-8.

48. Vlodavsky I, Mohsen M, Lider O, et al. Inhibition of tumor metastasis by heparanase inhibiting species of heparin. Invasion Metastasis 1994-1995;14:290-302.

49. Garg HG, Mrabat H, Yu L, et al. Anti-proliferative effects of O-acyl-low-molecular-weight heparin derivatives on bovine pulmonary artery smooth muscle cells. Glycoconj J 2011;28:419-26.

50. Yu L, Garg HG, Li B, et al. Antitumor Effect of Butanoylated Heparin with Low Anticoagulant Activity on Lung Cancer Growth in Mice and Rats. Current Cancer Drug Targets 2010;10:229-41. 